\title{
Reduced training distance and a forage-only diet did not limit race participation in young
} Standardbred horses

\author{
S. Ringmark ${ }^{1 *}$, L. Roepstorff ${ }^{1}$, U. Hedenström ${ }^{2}$, A. Lindholm and A. Jansson ${ }^{1}$ \\ 'Department of Anatomy, Physiology and Biochemistry, Swedish University of Agricultural Sciences, P.O. Box 7011, 75007 Uppsala, Sweden; \\ 2Swedish National Centre for Trotting Education, Wången 110, 83593 Alsen, Sweden; sara.ringmark@slu.se; \# deceased
}

Received: 19 May 2017 / Accepted: 28 June 2017

(c) 2017 Wageningen Academic Publishers

OPEN ACCESS (c) $\underset{\mathrm{BY}}{\underset{\mathrm{NC}}{\mathrm{NC}} \mathrm{SA}}$

RESEARCH ARTICLE

\begin{abstract}
In this study, a survey was used to document the type and amount of training to which 2- to 3-year old Swedish Standardbred horses are generally subjected. Moreover, an experimental study was conducted to examine the ability to achieve conventional performance goals in 16 Standardbred geldings fed a forage-only diet and allocated to either a control training programme (C-group) or a training programme with the high intensity training distance reduced by $30 \%$ (R-group) from March as 2-year-olds until December as 3-year-olds. The median distance of high intensity training per week reported by professional trainers was $6,700 \mathrm{~m}$. In experimental horses, planned high intensity training/week was 6,315 and 4,288 $\mathrm{m}$ in $\mathrm{C}$-group and R-group, respectively. There was no difference between experimental training groups in ability to race. The proportion of experimental horses that passed a preparation race as 2-year-olds (100\%) and qualified for races (94\%) was greater $(P<0.05)$ than for the rest of the cohort (77 and 63\%), geldings of the same cohort (71 and $45 \%)$ and siblings of the experimental horses ( 84 and $69 \%$ ). The proportion of horses that raced (56\%) was equal to that of the cohort and of siblings (54\%), but greater than the proportion of cohort geldings $(35 \%, P<0.05)$. In experimental horses, total earnings until 7 years of age were correlated to exercise haematocrit as 3-year-olds $(r=0.51, P>0.05)$ and number of races $(r=0.55$, $P>0.05)$. Race record was correlated to $\mathrm{V}_{\mathrm{La} 4}$ as 3 -year-olds $(r=-0.75, P<0.01)$. It was concluded that a forage-only diet and shorter distance of high intensity training than commonly used in Standardbred training in Sweden do not appear to restrict ability to qualify for races and race before 4 years of age.
\end{abstract}

Keywords: race performance, forage, Standardbred trainers, exercise distance, interval training

\section{Introduction}

In Sweden, Standardbred racehorses are most commonly trained with the goal of starting their harness racing career at 2 or 3 years of age, but historically only $30-50 \%$ race before the age of four years (Swedish Trotting Association, 2014). Training usually starts as long yearlings ( 18 months). In the cohorts of 2007-2008, consisting of 6,868 horses, $67 \%$ passed a preparation race $(2,140 \mathrm{~m}$, velocity standardised to $10.5-11.4 \mathrm{~m} / \mathrm{s}$ ) as 2-year-olds, but before 4 years of age only $56 \%$ had qualified for races and $49 \%$ had actually raced. The main reason for poor performance in Standardbred horses is reported to be health problems (Bendroth, 1986), with the most common problem being lameness (Vigre et al., 2002). The risk of lameness seems to increase with increased volume of high intensity training (Estberg et al.,
1995; Hamlin and Hopkins, 2003). However, high intensity training is necessary to some extent to optimise aerobic capacity and enhance performance over distances typically raced by Standardbreds. A training programme where this amount of high intensity training is reduced could potentially lower the risk of injuries and would therefore comprise an interesting alternative.

Although Swedish Standardbred horse trainers are among the most successful trainers in the world, the training strategies they use have never been documented scientifically, so the amount of training to which 2- and 3 -year-old horses are generally subjected is unknown. Moreover, the amount of high intensity training required to reach the goal of racing before 4 years of age in Standardbred horses has not yet been studied. 
Feeding of starch-rich concentrates, which are commonly used to meet the high energy requirements of racehorses (Jansson and Harris, 2013), is also associated with various health problems (Luthersson et al., 2009; MacLeay et al., 2000; Tinker et al., 1997). Use of high-energy forage has been suggested as an alternative feeding strategy that could promote both good health and performance (Jansson and Lindberg, 2012). However, there have been few studies to date about feeding a high-energy, forage-only diet from breaking to racing (Ringmark et al., 2015).

The two main aims of this study were to: (1) document and quantify the amount and type of training generally used by Swedish professional Standardbred trainers of 2- and 3 -year-old Standardbred horses; and (2) document the ability to reach conventional performance goals in sixteen 2- to 3-year-old Standardbred horses fed a forage-only diet and allocated to either a control training programme or a training programme in which the high intensity training distance was reduced by $30 \%$. The goal was to show that: (1) the high intensity training distances to which Swedish 2- and 3-year-old horses are generally subjected exceed the distances in the experimental training used in the study; (2) Standardbred horses subjected to a reduced training programme will qualify for races and race before 4 years of age to the same extent as horses subjected to a control training programme; (3) race participation in experimental horses is not impaired compared with their cohort or siblings; and (4) it is possible to condition Standardbred horses fed a forage-only diet to qualify for races and race as 3-year-olds.

\section{Materials and methods}

The study comprised two parts; a survey where Standardbred trainers were interviewed about their training methods and an experiment where 16 Standardbred horses were trained from breaking with the goal to race before 4 years of age. Data from the experimental study, presenting details of horse health, growth and physiological response to training, have been reported previously in Ringmark et al. $(2013,2015,2016)$.

\section{Trainer survey}

In August 2014, 50 professional Standardbred trainers were invited to participate in a survey. These trainers were chosen with the criterion of training the largest number of horses among all professional trainers in Sweden (Swedish Trotting Association, 2014). The trainers were asked about how they performed high intensity training with 2-and 3-year-old horses in terms of training type, length of exercise bouts, number of exercise bouts/session and number of high intensity training sessions per week.

\section{Experimental study}

Sixteen Standardbred geldings (born 2009) were studied from January in the year they turned 2 years until December in the year they turned 3 . The study is a continuation of that by Ringmark et al. (2013) on the same horses as 1-year-olds. The study was conducted at the Swedish National Trotting School, Wången, and the protocol was approved by Umeå Local Ethics Committee (A 90-10, 2010-09-14) according to Swedish animal welfare regulations.

\section{Horses and training}

The horses mainly had an American pedigree, but eight horses also had some $(<27 \%)$ French ancestors. These eight horses were all tested by the SychroGait gene test (Capilet Genetics, Västerås, Sweden) and were all homozygous for the stop codon in the DMRT3 gene, which has been shown to negatively affect the ability for a balanced trot at high speed if heterozygous (Andersson et al., 2012). The horses were cared for and trained by high school students, under the supervision of professional trainers. From early September as 1-year-olds until 18 March as 2-year-olds, all horses received the same training programme (Ringmark et al., 2013, 2015). In March as 2-year-olds, the horses were divided into two groups that were balanced with respect to parameters known to affect performance (for example breeding index, breeder, sire, height, conformation and muscle fibre composition as described in Ringmark et al., 2015). One group was allocated to a control training programme (C-group) and the other to a reduced training programme (R-group) until December as 3-year-olds. All training expected to cause a heart rate $(\mathrm{HR})>180$ beats per min (bpm) was reduced by approximately $30 \%$ of the distance in R-group compared with the training in C-group. This high intensity training was performed twice a week (except during holidays) as heat training $(1,600 \mathrm{~m} /$ bout in $\mathrm{C}$ horses and 1,100 $\mathrm{m} /$ bout in $\mathrm{R}$ horses), interval training (four intervals in $\mathrm{R}$ horses and six intervals in C-horses) on the track (beginning in August as 2-year-olds) and uphill interval training on a slope (beginning in February as 3-year-olds, four intervals in R-horses and six intervals in C-horses).

\section{Diet and management}

Horses were stabled individually in boxes for approximately $16 \mathrm{~h} /$ day, 4-5 days/week, and spent the rest of the time in an outdoor paddock with access to shelters. Wood shavings were used as litter. Horses had ad libitum access to water from buckets or troughs. Horses were shod every five weeks and fitted with ice spikes during winter.

Horses were fed grass haylage ad libitum as described by Ringmark et al. (2013). From the end of April until October, some grass was available in the paddock. A total of five 
batches of haylage were used, the nutritive value of which is described in detail by Ringmark et al. (2017) (concentration range per kg dry matter: metabolisable energy 10.311.7 MJ, crude protein (CP) 93-164 g, neutral detergent fibre 460-569 g, water-soluble carbohydrates 9-164 g, Ca 3.6-5.6 g, P 2.1-3.2 g, Mg 1.1-2.3 g, dry matter 47-71\%). The diet was complemented with $0.25-1.0 \mathrm{~kg}$ (depending on haylage nutrient content) of a pelleted lucerne product (95\% lucerne, 5\% molasses, Lantmännen Krafft AB, Malmö, Sweden) to enhance mineral supplement intake (50-150 g of Miner Röd, Lantmännen Krafft AB or Protect E-Selen, Lantmännen Lantbruk, Malmö, Sweden) and meet the CP requirements (NRC, 2007). Salt was always provided from salt blocks in boxes and, from September as 2-yearolds, $15 \mathrm{~g} \mathrm{NaCl}$ were added to the lucerne due to expected increased sweat losses. Horses were dewormed in spring and autumn (Cydectin ${ }^{\circ}$ vet/Cydectin comp vet, Zoetis Manufacturing \& Research Spain, S.L, Girona, Spain).

\section{Performance}

An overall goal for all horses was to pass a qualification race $(2,140 \mathrm{~m},>11.8 \mathrm{~m} / \mathrm{s}$, an official requirement to ensure that horses are fit for true races) at the age of 3 years and also to start competing in official races as 3-year-olds. An interim goal was that horses as 2-year-olds should pass a preparation race. It was the trainer's decision when horses were adequately trained to participate in these races. Performance goals and training programme were established together with a reference group consisting of four professional trainers with international experience and were aimed to resemble common practice in the Swedish Standardbred racing industry, but with some reduction in the high intensity training distance. For comparisons of racing results, three reference groups were created. One reference group consisted of all Swedish Standardbred horses in the cohort of 2009 (3,611 horses) that were registered at a professional or amateur trainer on 1 February 2011 (2,408 horses). Since all horses in the study were gelded during their second winter and since sex may influence physiological response to exercise (Persson and Ullberg, 1974), as well as race performance (Physick-Sheard, 1986; Tanner et al., 2011), a second reference group consisting only of horses in the cohort of 2009 registered at a trainer by 1 February 2011 that were registered as geldings before March 2011 (89 horses) was also created. A third reference group was created based on siblings (same mother) of the experimental horses. A maximum of five older siblings closest in age per experimental horse was used to create a 'mean sibling' ( 5 siblings $n=9 ; 3-4$ siblings $n=4 ; 1-2$ siblings $\mathrm{n}=3$, in total 64 horses of which 58 were registered at a trainer). The siblings were in most cases by other sires than the experimental horses and therefore the genetic potential of the sires of siblings and experimental horses was compared using their breeding index (Árnason, 1999). Sibling horses had been trained by a number of other trainers and had been fed a conventional cereal-forage diet (retrospective, anecdotal information). The proportion of horses that raced and the number of races performed were compared with values for the experimental horses.

In official races, the experimental horses were mostly raced ( $78 \%$ of races) by two professional trainers employed by the national trotting school. The logarithm (Ln) of earnings per race (Árnason, 1994) for the experimental horses in these races was compared with the logarithm of driver's earnings per start during three years prior to this study, in total 590 races. Race data were obtained from the Swedish Trotting Association (2014). No deeper analyses of race performance, such as comparisons of race times or earnings in R-group and C-group, were performed in this study, since the number of horses and also the number of races undertaken were low.

However, retrospectively, performance data from horses' race careers until December 2016, when they were 7 years old, were obtained from the Swedish Trotting Association (2017) to be used to study correlations with other parameters examined, as described below as well as performance comparisons with cohort gelding reference group.

\section{Statistical analysis}

All statistical analyses were performed in Statistical Analysis Systems package 9.3 (SAS Institute Inc., Cary, NC, USA). Differences were considered significant at $P<0.05$.

Differences between the experimental training programme and training programmes used by trainers in the survey were tested using a one-sample $t$-test. A GLM procedure with group as fixed effect and Tukey's test were used for analysis of differences between training groups in the ability to reach the performance goals, number of starts in true races, distance of high intensity training performed, differences in performance parameters between the experimental horses and the siblings and cohort geldings and also differences in natural logarithm of earnings (LnSEK) per race for the experimental horses and in other races with the same drivers.

The proportions of all horses in the study that passed a preparation race, passed a qualification race and participated in a true race were compared with the corresponding proportions for the cohort and cohort gelding reference groups by a $x^{2}$-test. Pearson's correlation test was used to test for possible correlations between record (2,140 $\mathrm{m}$ autostart), earnings and number of starts until December 2016 (Swedish Trotting Association, 2017), when horses were 7 years old, and body characteristics (height at withers, height at croup, body weight, body length, body condition score, subcutaneous fat at croup and thickness of $m$. longisimus dorsi as measured in Ringmark et al. $(2013,2017)$. Correlations with physiological 
response to exercise in terms of post exercise lactate, recovery heart rate, exercise haematocrit and $\mathrm{V}_{\mathrm{La} 4}$ (velocity at plasma lactate concentration of $4 \mathrm{mmol} / \mathrm{l})$, as measured in Ringmark et al. (2015), were also tested by Pearson's correlation.

\section{Results}

\section{Trainer survey}

Complete answers were received from 41 trainers. Two were excluded from the analysis because their training programme design did not include any specified high intensity training sessions. One used long exercises at slow speeds and the other used a cross-country track with varying unspecified incline. The 39 trainers included in the final results (Table 1) trained a total of 2,401 horses, which corresponded to approximately $13 \%$ of the Swedish Standardbred horses in training (Swedish Trotting Association, 2014). All trainers used interval training, 30 trainers used heat training and eight trainers used uphill interval training.

\section{Experimental training programmes}

The mean weekly planned high intensity training for horses as both 2- and 3-year-olds was 6,315 $\mathrm{m}$ in C-group and 4,288 $\mathrm{m}$ in R-group (Table 1). The mean for both groups was 5,302 m, which was less than the mean distance/week used by the professional trainers in the survey $(6,571 \pm 2,320 \mathrm{~m}, P<0.05)$. Compared with horses trained by the professional trainers in the survey, horses in C-group were subjected to less high intensity exercise as 3-year-olds, but there were no differences in trained distance/week as 2-year-olds or in total as 2- and 3 -year-olds (Table 1). Horses in R-group were subjected to less high intensity training per week as both 2- and 3-yearolds and also shorter exercise distances/session during both heat training and interval exercise. When performing heat training, trainers in the survey used longer exercise bouts than those to which horses in both experimental training programmes were subjected (Table 1).

Table 1. Characterisation of the planned training of 2- and 3-year-old horses at 39 professional Swedish Standardbred trainers (mean \pm standard deviation, median within brackets); and planned training programmes (control (C) or reduced by $30 \%$ of the high intensity training distance (R)) used in an experimental study including 16 2- to 3-year-old Standardbred horses (8 in $C$ and $R$, respectively).

\begin{tabular}{|c|c|c|c|c|c|c|c|c|c|c|}
\hline \multicolumn{2}{|l|}{ Training type } & \multicolumn{3}{|c|}{ Trainer responses } & \multicolumn{6}{|c|}{ Experimental horses ${ }^{1,2}$} \\
\hline & & \multirow[t]{2}{*}{ 2-year-olds } & \multirow[t]{2}{*}{ 3-year-olds } & \multirow[t]{2}{*}{ 2+3-year-olds } & \multicolumn{2}{|c|}{ 2-year-olds } & \multicolumn{2}{|c|}{ 3-year-olds } & \multicolumn{2}{|c|}{$2+3$-year-olds } \\
\hline & & & & & C & $\mathbf{R}$ & C & $\mathbf{R}$ & C & $\mathbf{R}$ \\
\hline \multirow[t]{3}{*}{ Heat } & Part of sessions, $\%$ & $35 \pm 27$ & $27 \pm 27$ & $31 \pm 27$ & 79 & 79 & 49 & 49 & 64 & 64 \\
\hline & Distance/bout, m & $\begin{array}{l}2,032 \pm 382 \\
(2,000)\end{array}$ & $\begin{array}{l}2,032 \pm 288 \\
(2,000)\end{array}$ & $\begin{array}{l}2,028 \pm 253 \\
(2,000)\end{array}$ & $1,600^{*}$ & $1,100^{*}$ & $1,600^{*}$ & $1,100^{*}$ & $1,600^{*}$ & $1,100^{*}$ \\
\hline & Distance/session, m & $\begin{array}{l}3,284 \pm 1,390 \\
(3,300)\end{array}$ & $\begin{array}{l}3,674 \pm 1,254 \\
(4,000)\end{array}$ & $\begin{array}{l}3,489 \pm 1,246 \\
(3,600)\end{array}$ & 3,200 & $2,200^{*}$ & $3,200^{*}$ & $2,200^{*}$ & 3,200 & $2,200^{*}$ \\
\hline \multirow[t]{3}{*}{ Interval } & Part of sessions, $\%$ & $58 \pm 28$ & $63 \pm 29$ & $61 \pm 29$ & $21^{*}$ & $21^{*}$ & $9^{*}$ & $9^{*}$ & $14^{*}$ & $14^{*}$ \\
\hline & Distance/bout, m & $\begin{array}{l}612 \pm 110 \\
(600)\end{array}$ & $\begin{array}{l}638 \pm 194 \\
(600)\end{array}$ & $\begin{array}{l}621 \pm 134 \\
(625)\end{array}$ & 700 & 700 & 700 & 700 & 700 & 700 \\
\hline & Distance/session, m & $\begin{array}{l}3,177 \pm 762 \\
(3,000)\end{array}$ & $\begin{array}{l}3,643 \pm 1,250 \\
(3,500)\end{array}$ & $\begin{array}{l}3,388 \pm 861 \\
(3,300)\end{array}$ & 4,200 & $2,800^{*}$ & 4,200 & $2,800^{*}$ & 4,200 & $2,800^{*}$ \\
\hline \multirow[t]{5}{*}{ Uphill interval } & Part of sessions ${ }^{2}, \%$ & $4 \pm 10$ & $9 \pm 19$ & $6 \pm 16$ & - & - & 42 & 42 & 42 & 42 \\
\hline & Distance/bout, m & $\begin{array}{l}700 \pm 412 \\
(500)\end{array}$ & $\begin{array}{l}655 \pm 345 \\
(525)\end{array}$ & $\begin{array}{l}650 \pm 134 \\
(525)\end{array}$ & & & 600 & 600 & 600 & 600 \\
\hline & Distance/session, $\mathrm{m}$ & $\begin{array}{l}2,533 \pm 589 \\
(2,800)\end{array}$ & $\begin{array}{l}3,170 \pm 595 \\
(3,500)\end{array}$ & $\begin{array}{l}2,910 \pm 378 \\
(2,900)\end{array}$ & & & 3,600 & $2,400^{*}$ & 3,600 & $2,400^{*}$ \\
\hline & Number of sessions/week & $2 \pm 1$ & $2 \pm 0$ & $2 \pm 0$ & 1.8 & 1.8 & 1.8 & 1.8 & 1.8 & 1.8 \\
\hline & Distance/week, m & $\begin{array}{l}5,707 \pm 2,553 \\
(5,600)\end{array}$ & $\begin{array}{l}7,434 \pm 3,119 \\
(7,400)\end{array}$ & $\begin{array}{l}6,571 \pm 2,320 \\
(6,700)\end{array}$ & 6,270 & $4,277^{*}$ & $6,357^{*}$ & $4,299^{*}$ & 6,315 & $4,288^{*}$ \\
\hline
\end{tabular}




\section{Race participation}

All 16 horses in the experimental study passed a preparation race between May and October as 2-year-olds (Table 2). Fifteen horses (8 in C-group and 7 in R-group) passed a qualification race between May and November as 3-year-olds and nine horses (5 in C-group and 4 in R-group) participated in races between July and December as 3-year-olds (Table 2). There was no difference between the two training groups in ability to reach any of the performance goals or number of races $(P>0.05)$. There was also no difference between training groups in distance of high intensity training performed prior to qualification for races (C-group $255 \pm 67 \mathrm{~km}, \mathrm{R}$-group $234 \pm 39 \mathrm{~km} ; P>0.05$ ) or to first race (C-group $261 \pm 51 \mathrm{~km}$, R-group $274 \pm 33 \mathrm{~km} ; P>0.05)$.

The proportions of horses in the cohort reference group that passed a preparation race and a qualification race before 4 years of age were lower $(P<0.0001)$ than the corresponding proportions of experimental horses, but there was no difference in the proportion of horses that participated in true races (Table 2). The proportions of horses in the cohort gelding reference group that passed a preparation race, qualified for races and raced before 4 years of age were lower $(P<0.0001)$ than the corresponding proportions of experimental horses. When compared with the sibling reference group, there was no difference in the proportion of siblings that raced (Table 2) or the mean number of races performed before 4 years of age (siblings $2.9 \pm 0.6$, experimental horses $1.6 \pm 0.6 ; P>0.05$ ). The proportions of experimental horses that passed a preparation and a qualification race were greater than those of the siblings $(P<0.05)$. Breeding index for the sires of the experimental horses was lower than that for the sires of the siblings $(107 \pm 2$ and $111 \pm 2$, respectively; $P=0.04$ ).

In total during the study period, 27 races were undertaken by the experimental horses. The drivers racing the experimental horses earned less prize money/race with other horses they had been racing in the previous three years than with the experimental horses $(1.07 \pm 0.02$ and $0.05 \pm 0.78 \mathrm{LnSEK} /$ race, respectively; $P=0.04)$.

After the study finished, the horses were sold to new owners all over Sweden (Swedish Trotting Association, 2016). Twelve horses were registered at a trainer at some time during the first year after the study finished and 10 of these raced at least once during that year (2013). Six won at least one race within one year after the study finished. Mean total number of lifetime races undertaken until December 2016 (when horses were 7 years old) was 24 (range 0-76) and mean earnings were 129,064 SEK (range $0-819,269$ SEK). Compared with geldings of the cohort there were no difference in number of races, earnings or record until $31^{\text {st }}$ of December 2016 ( $24 \pm 6$ vs $19 \pm 2$ races, $10.1 \pm 0.6$ vs $9.4 \pm 0.2 \mathrm{LnSEK}$ and $1 \mathrm{~min} 16.2 \pm 0.5 \mathrm{SEK} / \mathrm{km}$ vs $1 \mathrm{~min} 15.9 \pm 0.3 \mathrm{SEK} / \mathrm{km}$ [LsMeans \pm standard error] for experimental horses vs reference cohort geldings, $P>0.05$ ).

Mean peak haematocrit $(56 \pm 2)$ from five $\mathrm{V}_{\mathrm{La} 4}$-tests performed when horses were 3 years old was positively correlated with 7-year earnings (Table 3) and number of starts. Mean $\mathrm{V}_{\mathrm{La} 4}$ as 3-year-olds $(10.8 \pm 0.2 \mathrm{~m} / \mathrm{s})$ was negatively correlated with race record ( $1 \mathrm{~min} 16.1 \pm 2.7 \mathrm{~s} / \mathrm{km}$ ) until 7 years (Table 3). No other correlations with exercise response parameters or body characteristics were found with starts or earnings.

Table 3. Correlations between mean peak haematocrit and mean $V_{\mathrm{La} 4}$ from five $\mathrm{V}_{\mathrm{La} 4}$ tests performed in experimental horses as 3 -year-olds and performance data as 7 -year-olds. ${ }^{1}$

\begin{tabular}{llll} 
& Race record (s) & Number of starts & Earnings, SEK \\
Haematocrit & n.s. & $r=0.55, P<0.05$ & $r=0.51, P<0.05$ \\
$V_{\text {La4 }}$ & $r=-0.75, P<0.01$ & n.s. & n.s. \\
\hline 1 n.s. = not significant. & &
\end{tabular}

Table 2. Performance of experimental horses allocated to a control training programme (C-group) or a programme with high intensity training distance reduced by $30 \%$ (R-group) and of three reference groups consisting of horses of the same cohort in training, horses of the same cohort that were gelded before March as 2-year-olds and siblings of the experimental horses.

\begin{tabular}{|c|c|c|c|c|c|c|}
\hline & \multicolumn{2}{|c|}{ Experimental horses } & \multicolumn{4}{|c|}{ Reference $^{1}$} \\
\hline & C-group & R-group & All & Cohort & Cohort geldings & Siblings \\
\hline Preparation race, (n) \% & (8) 100 & (8) 100 & (16) 100 & $(1,861) 77^{*}$ & (63) $71^{*}$ & (49) $84^{*}$ \\
\hline Qualification race, (n) \% & (8) 100 & (7) 88 & (15) 94 & $(1,520) 63^{*}$ & $(40) 45^{*}$ & (40) $69^{*}$ \\
\hline Raced before 4 years, (n) \% & (5) 63 & (4) 50 & (9) 56 & $(1,299) 54$ & $(31) 35^{*}$ & (34) 54 \\
\hline
\end{tabular}




\section{Discussion}

\section{General}

This is the first study to document the amount and type of high intensity training to which 2- and 3-year-old Swedish Standardbred horses are generally subjected. The results revealed that interval training, which has been shown to be successful in human runners (Laursen, 2010), is the dominant training method used among Swedish Standardbred trainers. This may be in contrast to common practice in e.g. US Standardbred training (Malinowski and Avenatti, 2015). In accordance with our aim for the experimental part of the study, we showed that it is possible to train horses to qualify for races and race before 4 years of age even if total training distance and length of exercise bouts are reduced compared with the distances to which Swedish 2-and 3-year-old horses are generally subjected. Moreover, the results demonstrated that it is possible to condition Standardbred horses fed a forage-only diet to qualify for races and race as 3-year-olds.

\section{Trainer survey and comparison to experimental study}

Almost all trainers participating used high intensity exercise twice a week on a regular basis, but two trainers were exceptions in that they did not use any common high intensity training at all, which illustrates the low variation in training approaches for Standardbred horses. As heat training is the form that is most similar to true racing, it is not surprising that most trainers used this to some extent to prepare horses for races. However, as already mentioned, the most common training form was interval training, although the length and amount of intervals varied.

On comparing the training in the experimental study with that reported by the trainers in the survey, the present study indicated that the distance of high intensity training to which most young Swedish Standardbred horses are subjected could be reduced without affecting race participation. The experimental training programme (mean for $\mathrm{C}$ - and R-group) used from March as 2-year-olds resulted in 5,302 $\mathrm{m}$ of planned high intensity training/week, which was 1,269 $\mathrm{m}$ less than the mean and 1,398 $\mathrm{m}$ less than the median in the trainer survey. Furthermore, during heat training, which is the training type covering the longest distance in a single bout, the experimental horses exercised $\geq 400 \mathrm{~m}$ shorter distance/bout than the mean and median distances used by the trainers. This resulted in a $789 \mathrm{~m}$ shorter high intensity training distance per session in the experimental programme than used by the trainers in the survey. In summary, the design of the experimental training programmes resulted in less training than the level to which at least half the horses in the trainer survey were subjected.

\section{Performance in experimental horses}

Horses subjected to the reduced training programme qualified for races and raced to an extent that was not different from horses in the control group. This indicates that the training programmes were equally efficient in achieving the performance goals. Interestingly, there was no difference in high intensity exercise distance performed before qualifying for races and racing. This was due to more days being lost to training in C-group (Ringmark et al., 2016) when horses were not considered to be fit enough to participate in planned training. More days lost to training in C-group is also in accordance with the finding that increased levels of high intensity training may increase the risk of health problems (Estberg et al., 1995; Gaustad et al., 1995; Hamlin and Hopkins, 2003). However, the present study showed that a certain amount of accumulated high intensity exercise is required to reach race condition and that this may be achieved either by the use of conventional (or slightly less than conventional) exercise sessions, but with fewer sessions in total, or by the use of a reduced training distance during exercise sessions, but with a higher exercise session frequency.

The experimental horses succeeded above expectations in participation in preparation, qualification and true races compared with their cohort, geldings of the cohort and siblings. Even though experimental horses were managed and exercised by more or less inexperienced teenagers, and were by sires with less genetic potential than the sires of their siblings, experimental horses passed both preparation and qualification races to a higher extent than all three reference groups. They also earned more prize money per race than horses driven by the same drivers previously, indicating that driver skills was not the main reason of their performance, although the performance capacity of the horses driven by the same drivers previously is unknown. The proportion of experimental horses racing before 4 years of age was also higher than the proportion of trained geldings of the same cohort, which may be a more representative reference group than the whole cohort, as sex may influence race performance (Tanner et al., 2011). One possible reason for these differences could be a clearer definition of performance goals for the experimental horses than for horses in regular training. However, passing a preparation race is likely a goal for most horses in professional training as 2-year-olds, as a prize of 20,000 SEK is given to all owners of horses finishing within an ideal time. Another reason could be the lower training volume as 2-year-olds compared with that used by trainers in the survey. A third reason may be that the forage-only diet fed to the experimental horses had a positive effect on performance capacity, for example resulting in a reduced lactate response to exercise (Jansson and Lindberg, 2012), better cartilage quality (Glade and Belling, 1984) and less reactive responses to fear stimuli (Bulmer et al., 2015), enhancing horse trainability. It is interesting to speculate 
on other explanations for this early high performance of the experimental horses. It could be influenced by nutrition, by management, by details in training not captured in this study or by other factors such as genetics and mental traits. The most important consideration is that it indicates the necessity for further studies with more controlled, preferably quantitative, methods for registering factors influencing health and performance. The lower proportion of horses racing before 4 years of age than the proportion of horses passing preparation and qualification races reflects the difficulty in training horses to be fit to race. The fitness and speed required to participate and win even the lowest classes of races are most likely close to the maximal genetic potential of some horses. Among the seven horses not reaching the goal of racing before 4 years, three failed due to a trauma not related to the training programme, while in the rest health problems with their locomotor apparatus (Ringmark et al., 2016) and insufficient fitness were the reasons. The lack of difference in performance until 7 years compared to the gelding reference group indicates that the management of the experimental horses until 3 years of age did not limit their later performance ability in comparison with other horses with a conventional background. However, since the genetic potential of the gelding reference group is not known it is unclear if these horses were expected to perform similar, better or worse that the experimental horses. We could only speculate on that our horses had lower expected genetic potential since they had not been sold by the breeders before the study began (at the age of 1.5 years).

\section{The effect of physiological characters on performance}

Previous studies have shown correlations between body characteristics and physiological response to exercise and race performance (Courouce et al., 1997; Dobec et al., 1994; Kearns et al., 2002; Thafvelin, 1990). In the present study, both $\mathrm{V}_{\mathrm{La} 4}$ and haematocrit as 3-year-olds were found to correlate with race performance parameters. A negative relationship between true performance (race time) and blood volume and haemoglobin has been demonstrated previously in Standardbred horses (Persson, 1968). A similar negative relationship between $\mathrm{V}_{\mathrm{La} 4}$ and race record (Lindner, 2010), and a positive relationship between $\mathrm{V}_{\mathrm{La} 4}$ and race performance (Courouce et al., 1997; Leleu et al., 2005), have also been reported previously.

\section{Summary and future perspectives}

In summary, the reduced training programme resulted in similar ability to pass a preparation race, qualify for races and race before 4 years of age as for horses in the control training programme, but with fewer days lost to training, indicating better health status in the reduced training group (Ringmark et al., 2016). Due to the difference in days lost to training, there was no difference in the total distance of high intensity training performed before first race between the two training groups. However, horses in the control group showed greater cardiovascular training adaptation with reduced working and recovery heart rate and higher haematocrit (Ringmark et al., 2015). The latter were also correlated with total earnings until the age of 7 , which may indicate a benefit for the control training programme in terms of race performance. On the other hand, $\mathrm{V}_{\mathrm{La} 4}$ in the horses as 3-year-olds did not differ between training groups and was correlated to race record, which would indicate a negligible, if any, difference in performance capacity between the training groups. In order to increase the welfare of future race horses and the sustainability of the horse racing industry, more knowledge about the effects of variations in the components (volume, repetition, frequency and intensity) affecting training response, performance and health is required. In the future, we hope to see more studies using emerging quantitative methods and a holistic approach to examine the impact of long-term training strategies on injury prevention and true performance of race horses. The present study was a first step in examining the effects and use of a reduced exercise distance, but there are many more factors waiting to be explored.

The overall conclusion reached in this study is that a forageonly diet and a reduced distance of high intensity training compared with the level commonly applied in Sweden appear not to restrict ability in Standardbred horses to qualify for races and race before 4 years of age.

\section{Acknowledgements}

The authors thank all staff and students at Wången. Special thanks to the trainers Roger Persson and Lars-Åke Svärdfeldt. Thanks also to the reference group of trainers, Stig H Johansson, Thomas Uhrberg and Jan Halberg, for help with designing the training programmes. We would also like to thank all the trainers who participated in the survey and Svensk Travsport for information. Great thanks also to Trioplast AB, Dow Chemicals, Swedish Trotting Association, Swedish Horse Racing Totalisator Board and the Swedish Horse Council Foundation for financial support and to Polar Finland for providing heart rate recorders, Scandivet for lactate analyses and Thermobar $\mathrm{AB}$ for sponsoring with thermobars.

\section{References}

Andersson, L.S., Larhammar, M., Memic, F., Wootz, H., Schwochow, D., Rubin, C.-J., Patra, K., Árnason, T., Wellbring, L., Hjalm, G., Imsland, F., Petersen, J.L., McCue, M.E., Mickelson, J.R., Cothran, G., Ahituv, N., Roepstorff, L., Mikko, S., Vallstedt, A., Lindgren, G., Andersson, L. and Kullander, K., 2012. Mutations in DMRT3 affect locomotion in horses and spinal circuit function in mice. Nature 488: 642-646. 
Árnason, T., 1994. The importance of different traits in genetic improvement of trotters. In: Proceedings of the $5^{\text {th }}$ World Congress on Genetics applied to Livestock Production. August 7-12, 1994. University of Guelph, Guelph, Ontario, Canada, pp. 462-470.

Árnason, T., 1999. Genetic evaluation of Swedish standard-bred trotters for racing performance traits and racing status. Journal of Animal Breeding and Genetics - Zeitschrift fur Tierzuchtung Und Zuchtungsbiologie 116: 387-398.

Bendroth, M., 1986. Orsaker till låg startfrekvens hos 3-4-åriga travhästar. Svensk Veterinärtidning 38: 7-10.

Bulmer, L., McBride, S., Williams, K. and Murray, J.-A., 2015. The effects of a high-starch or high-fibre diet on equine reactivity and handling behaviour. Applied Animal Behaviour Science 165: 95-102.

Courouce, A., Chatard, J.C. and Auvinet, B., 1997. Estimation of performance potential of Standardbred trotters from blood lactate concentrations measured in field conditions. Equine Veterinary Journal 29: 365-369.

Dobec, R.L., Borger, M.L. and Neal, S.M., 1994. Correlation of realtime ultrasonic measures of fat and longissimus muscle area in Standardbred horses with lifetime racing record and lifetime winnings. Journal of Animal Science 72: 44.

Estberg, L., Gardner, I.A., Stover, S.M., Johnson, B.J., Case, J.T. and Ardans, A., 1995. Cumulative racing-speed exercise distance clusters as risk factor for fatal musculoskeletal injury in Thoroughbred racehorses in California. Preventive Veterinary Medicine 24: 253-263.

Gaustad, G., Kjaersgaard, P. and Dolvik, N.I., 1995. Lameness in 3-yearold Standard-bred trotters influence of parameters determined during the first year of life. Journal of Equine Veterinary Science 15: 233-239.

Glade, M.J. and Belling, T.H., 1984. Growth plate cartilage metabolism, morphology and biochemical-composition in overfed and underfed horses. Growth 48: 473-482.

Hamlin, M.J. and Hopkins, W.G., 2003. Retrospective trainer-reported incidence and predictors of health and training-related problems in Standardbred racehorses. Journal of Equine Veterinary Science 23: 443-452.

Jansson, A. and Harris, P.A., 2013. A bibliometric review on nutrition of the exercising horse from 1970 to 2010. Comparative Exercise Physiology 9: 169-180.

Jansson, A. and Lindberg, J., 2012. A forage-only diet alters the metabolic response of horses in training. Animal 6: 1939-1946.

Kearns, C.F., McKeever, K.H., Kumagai, K. and Abe, T., 2002. Fat-free mass is related to one-mile race performance in elite Standardbred horses. Veterinary Journal 163: 260-266.

Laursen, P.B., 2010. Training for intense exercise performance: highintensity or high-volume training? Scandinavian Journal of Medicine and Science in Sports 20: 1-10.

Leleu, C., Cotrel, C. and Courouce-Malblanc, A., 2005. Relationships between physiological variables and race performance in French Standardbred trotters. Veterinary Record 156: 339-342.

Lindner, A.E., 2010. Relationships between racing times of Standardbreds and v(4) and v(200). Journal of Animal Science 88: 950-954.
Luthersson, N., Nielsen, K.H., Harris, P. and Parkin, T.D.H., 2009. Risk factors associated with equine gastric ulceration syndrome (EGUS) in 201 horses in Denmark. Equine Veterinary Journal 41: 625-630.

MacLeay, J.M., Valberg, S.J., Pagan, J.D., Xue, J.L.L., De la Corte, F.D. and Roberts, J., 2000. Effect of ration and exercise on plasma creatine kinase activity and lactate concentration in Thoroughbred horses with recurrent exertional rhabdomyolysis. American Journal of Veterinary Research 61: 1390-1395.

Malinowski, K. and Avenatti, R., 2015. Training Standardbred trotters and pacers. In: Hodgson, D., McGowan, C. and McKeever, K. (eds.) The athletic horse: principles and practice of equine sports medicine, $2^{\text {nd }}$ edition. Elsevier, St. Louis, MO, USA, pp. 305-313.

National Research Council (NRC), 2007. National Research Council Committee nutrient requirements of horses. National Academies Press, Washington, DC, USA.

Persson, S.G.B. and Ullberg, L.E., 1974. Blood volume in relation to exercise tolerance in trotters. Journal of the South African Veterinary Association 45: 293-299.

Persson, S.G.B., 1968. Blood volume, state of training and working capacity of race horses. Equine Veterinary Journal 1: 52-62.

Physick-Sheard, P.W., 1986. Career profile of the Canadian Standardbred. Influence of age, gait and sex upon chances of racing. Canadian Journal of Veterinary Research 50: 449-456.

Ringmark, S., Jansson, A., Lindholm, A., Hedenström, U. and Roepstorff, L., 2016. A 2.5 year study on health and locomotion symmetry in young Standardbred horses subjected to two levels of high intensity training distance. Veterinary Journal 207: 99-104.

Ringmark, S., Lindholm, A., Hedenstrom, U., Lindinger, M., Dahlborn, K., Kvart, C. and Jansson, A., 2015. Reduced high intensity training distance had no effect on VLa4 but attenuated heart rate response in 2-3-year-old Standardbred horses. Acta Veterinaria Scandinavica 57: 17 .

Ringmark, S., Revold, T. and Jansson, A., 2017. Effects of training distance on feed intake, growth, body condition and muscle glycogen content in young Standardbred horses fed a forage-only diet. Animal: 1-9.

Ringmark, S., Roepstorff, L., Essen-Gustavsson, B., Revold, T., Lindholm, A., Hedenstrom, U., Rundgren, M., Ogren, G. and Jansson, A., 2013. Growth, training response and health in Standardbred yearlings fed a forage-only diet. Animal 7: 746-753.

Swedish Trotting Association, 2014-2017. Database of Swedish Trotting Association. Available at: www.travsport.se.

Tanner, J.C., Rogers, C.W. and Firth, E.C., 2011. The relationship of training milestones with racing success in a population of Standardbred horses in New Zealand. New Zealand Veterinary Journal 59: 323-327.

Thafvelin, B., 1990. The genetic variation in conformation of Standardbred trotters and the relationship between conformation and performance. SLU, Uppsala, Sweden, pp. 1-18.

Tinker, M.K., White, N.A., Lessard, P., Thatcher, C.D., Pelzer, K.D., Davis, B. and Carmel, D.K., 1997. Prospective study of equine colic risk factors. Equine Veterinary Journal 29: 454-458.

Vigre, H., Chriel, M., Hesselholt, M., Falk-Ronne, J. and Ersboll, A.K., 2002. Risk factors for the hazard of lameness in Danish Standardbred trotters. Preventive Veterinary Medicine 56: 105-117. 